\title{
Researcher's Reflection: Learning About Menstruation Across Time and Culture
}

\author{
Sheryl E. Mendlinger
}

In 1969, at the age of 18, after graduating high school in Houston, Texas, I packed a steamer trunk with a year's supply of shampoo, toilet paper, and tampons and went to study abroad in Israel. All these products were outrageously expensive, and tampons and pads were not readily available at that time. I soon found that many women in Israel were still using wads of cotton wool to absorb their menstrual blood, something I had never seen in the USA. I had no idea that 30 years later the idea of tampons would lead to a topic of research for a Ph.D. dissertation. Over the course of that year I started to learn the language, adapt to the culture of the host society, and made my decision to remain in the country. Several years later, I married, had children, and was constantly navigating this duality through the challenges of bilingualism and biculturalism within the family as well as the general society. As a new immigrant I began adapting to the new culture yet holding onto many of the beliefs and traditions that I brought from my home country.

The impetus for this research began when my teenage daughter came home from school in the early 1990s (born in Israel and raised in Beer Sheva, in the Negev region) hearing from her friends "if you use tampons you could lose your virginity." I thought back to my mother who had introduced me to tampons in the 1960s, as a teenager growing up in the USA, she certainly would not have given me a product that would cause me to lose my 'virginity.' Because we lived in a diverse community in southern Israel (Negev) and many of the parents of my daughter's friends had immigrated from North Africa, Iraq, and Eastern Europe to Israel, I began thinking about what we learn from our mothers, even about menstrual products, is significant in understanding generational and cultural differences that can impact our lives in so many ways. Years later when I chose my topic for my Ph.D., I examined mother-daughter dyads from North Africa, Ethiopia, 
Europe, North America, the Former Soviet Union, and Israel in order to better understand how mothers transmit knowledge about health behaviors, specifically about menstruation, to their daughters.

Israel is an immigrant ethnically diverse society. The mass immigration to Israel that began in the $1950 \mathrm{~s}$, and continues today, brought a wide variety of cultural traditions to the country. One of the long-term effects of immigration has been the ongoing differentiation of the Jewish population based on countries of origin within an evolving Israeli identity and norm. The data collection took place at a time in Israel's history when there was a mass immigration from two countries in particular. Between 1989 and 2000, over a million people immigrated to Israel from the Former Soviet Union and tens of thousands from Ethiopia. Over 10\% settled in the Negev area where we lived, and that became a living sociological laboratory in which disparities of health could be examined.

Through my research ${ }^{1}$ I was able to capture the acculturation process of some of the daughters in real time. At the time of my data collection, there was limited research conducted on intergenerational aspects of mothers and adult daughters who took part in the same study, and even fewer studies that looked specifically about intergenerational menstrual knowledge transmission, especially between mothers and daughters who immigrated from a diverse set of populations to the same country. This rapid increase in immigrant population, in such a short time span, affected various cultural aspects of the community and specifically in the area of women's health. Long-range effects of immigration are often seen not only among the first generation of immigrants, but in the second generation as well.

The qualitative ethnographic study included data collected from 48 in-depth interviews from four mother-daughter dyads from six groups that were defined by the origin of the mothers, who were born in (1) Israel; or immigrated to Israel from: (2) North Africa; (3) Europe; (4) the Former Soviet Union (FSU); (5) the United States or Canada; and (6) Ethiopia. These groups represent a cross section of the local Jewish population in the Negev, Israel. Although these women are Israeli citizens, I refer to them as Israeli, North African, European, FSU, USA, and Ethiopian for clarity sake only. ${ }^{2}$

Considering that I had emigrated years before from the USA, I occupied a unique researcher's vantage point that enabled me to better understand the challenges that immigrants have when moving between countries. When the women were asked to talk about their experience at puberty, they often constructed their story related to their physical body development and integrated it within the context of the menarche experience. For the most part, women remembered the actual day, even when it was decades ago. To capture the types of knowledge that mothers passed on to their daughters, I developed a model of knowledge acquisition for learning about menstruation that articulated four types: traditional, embodied, technical, and authoritative. A central thread that runs in this model is that knowledge acquisition is different in an ethnically pluralistic context than in one more homogenous. 


\section{The “Slap” Heard 'Round the World' and Other Menarcheal Traditions}

One of the most interesting aspects of this research is the stories the women shared about their menarcheal (first period) experiences. In many traditional cultures there were ceremonies, rituals, and traditions that were passed from one generation to another that may give either a positive or negative valence to the way women view menstruation. Traditional knowledge and rituals often provide strong emotional support for daughters allowing a comfortable transition through this key developmental stage. Several women whose origins were from Europe spoke about "the slap." One mother told the story that when she got her first period her mother slapped her across the face, which she did to both of her daughters, "my family always passed down traditions," yet there was uncertainty what it meant. While the mother said the reason was "something about the blood coming back," the daughter said it was something about "the blood not going to your mind." The actual historical reasons for the slap are unknown. However different explanations include: the manner in which the act of slapping took place could determine the duration of menstruation; it was necessary for a girl when she becomes a woman as protection against disgrace; and the rush of blood will make the girl have a wonderful color in her cheeks throughout her life. The uncertainty surrounding this ritual exemplifies that even as traditions continue, their rationales are often lost.

Women who immigrated from North Africa and Ethiopia looked at the onset of menstruation as a milestone that symbolized fertility, therefore achieving status in the traditional society. Several of the women born in North Africa spoke with joy and excitement when they reminisced about getting their periods for the first time and the celebrations that surrounded this event with mothers playing an integral role in this transition. Some of the traditions included mothers giving their daughters pieces of jewelry and preparing special foods and performing the ritual of putting three of the daughters' fingers in flour so that they should only get their period for three days. Another tradition is the oil ceremony in which mothers told their daughters to look and smile at their reflection in a bowl of olive oil, and then their faces were rubbed with oil. These girls were told that the image they saw on that day should continue and they should enjoy a happy life. The women noted that the oil would smooth a woman's passage into womanhood. This oil ceremony was accompanied by a festive meal with traditional foods including honey-dipped, oil-fried cakes. When these women, now elders, were asked if they continued this tradition with their daughters, they all answered an emphatic no, of course not. It appears that the change and adaptation to the new culture and environment took precedence over retaining certain cultural practices. But there were exceptions. For instance, I interviewed one daughter of American immigrants who grew up on a Kibbutz, a collective community. She spoke with excitement as she recalled when each girl in her age cohort got her period, they celebrated with gifts and a special party. 


\section{Cultural and Religious Prohibitions}

There are many religious customs and restrictions during menstruation related to the Jewish laws of family purity that include niddah, the time of separation; teuma, being unclean and untouchable; and tahara, the cleansing process following menstruating that religious Jewish women continue to observe today. An Ethiopian daughter told me that when you menstruate "you can't touch food for the Sabbath . . . my mother will not let me prepare food that is for the Sabbath." A North African mother shared, "it is forbidden to go into the Synagogue or hold the Torah Scrolls, or go to the cemetery since you are 'ritually impure', these were the things they always told us."

The older Ethiopian women talked about their experiences at menarche which included special foods that their mother's prepared, and then the young girl would go to the 'menstruation hut' where she would remain until the completion of her period. An Ethiopian mother noted "when you go to the hut someone brings you food and if you touch them, they must stay there as well ...." They looked forward to this time to be taken care of and pampered by the other women of the community. As another mother noted "in Ethiopia there is no rest until you go to the hut, only during menstruation the women rests," and her daughter explained, "the week away from chores was fun and a brief vacation from everyday life and being with friends and not having to work so hard." However, the mothers did not continue traditions, such as preparing special foods or going to the menstruation hut after they immigrated to Israel. ${ }^{3}$

\section{Technical Knowledge—“There Weren’t Pads, There Were Rags...”}

Several mothers from Israel, North Africa, and Europe reported using rags when they first got their periods. They told me "there weren't pads, there were rags, we just cut rags and we began with that, we would cut all sorts of strips of material and we would wash them and use them again ..." and "we would buy small white towels . . we would wash and boil them in some sort of box,. . . they would come out white like snow. . . ." Another daughter from Ethiopia said she used cotton until she read in a magazine about pads. Many of the mothers and their daughters from almost all the countries reported using cotton and then over the years, they started to use pads and or tampons when they became more accessible. Often the daughters taught the mothers about products. ${ }^{4}$

The mothers from the former Soviet Union (FSU) immigrated either in the 1970s or late 1980s-1990s began menstruating before immigration and spoke about using cotton wool when they first got their periods because "we didn't have other things." Mothers who immigrated in the 1970s also noted that "after immigration I used pads . . I never heard about pads or tampons 
in Russia, only here [in Israel]," and another mother noted "back then there weren't any, when I came to Israel [in 1971] tampons were already here." It appears that pads and tampons were not available to the mass population in the FSU in the 1970s. On the other hand a mother from the FSU who only immigrated to Israel in 1994 spoke about using other products: "I knew about tampons when my daughter was about 14-15 [about 1990-1991], they were already in the stores [in the FSU], when there was something new, we started to experiment on ourselves." It appears that accessibility of menstrual products has a great influence on what women use, and the methods of menstrual care have changed over the last several decades. ${ }^{5}$

There were some interesting differences based on country of origin. The more traditional the women, especially those from North Africa and Ethiopia, the less they used tampons. The reasons they gave included: not wanting to touch oneself; not putting foreign objects inside their bodies; perceived loss of virginity; and hearing in the media that tampons caused infections and cancer. All the mothers I interviewed from the United States and Canada, however, used pads and soon moved to tampons during their teenage years. Their daughters followed similar patterns. None of these women reported using cotton wool which led me to assume that since the mothers never used cotton wool, they did not recommend it to their daughters. These daughters began using tampons at a relatively early age, often younger than their Israeli contemporaries.

The use of products can have a profound effect on how women deal with menstruation in their daily lives. Many of the mothers spoke about restrictions and the inability to take part in certain activities that appear to be a direct result of how they handled menstruation. As an example, if one used cotton or pads it was almost impossible to swim or take part in certain sports activities. This may explain why women told me that it was not possible to swim while menstruating. However, the introduction of tampons enabled women greater mobility and therefore, freedom. For example, one daughter who immigrated from the FSU was a gymnast who never practiced or competed while menstruating. The first time she even heard about tampons was in the late 1990s when an Israeli woman introduced her to tampons. She was so delighted to have access to tampons she exclaimed, "the person who invented the tampons should get the Nobel prize."

The model of knowledge acquisition of health has been applied to other aspects of women's health behaviors that include: family planning and birth control ${ }^{6}$ informed decision making for breast cancer patients, ${ }^{7}$ and could be extended into further studies of learning about birth, breastfeeding, infant care, coping with marital conflict, and mid-life or older age health challenges. Furthermore, the results should allow health professionals to tailor the educational programs to the ways in which women form their approaches to critical health behavior. These educational programs can be developed to focus on various target groups within the population and to include health education 
that takes into account the broad spectrum of cultural aspects of the attitudes of health behavior in ethnically pluralistic cultures.

My research was the first undertaking of its kind that examined the intergenerational transfer of menstrual health knowledge and practices in Israel. Although the data was collected almost two decades ago, it remains relevant because it provides unique insight into the effects of mass immigration to a culturally diverse country. In addition, at the time of this study, the internet as a major source of information was not readily available in Israel to the general public, especially in the Hebrew language. Therefore, learning about menstruation was primarily based on verbal communication or written information. Today, as women are moving from one country to another, either by choice or through forced political or economic displacement, it becomes very important to understand the varied cultural beliefs and traditions of people on the move as they adjust to their new countries and home.

\section{Notes}

1. Sheryl E. Mendlinger and Julie Cwikel. 2005/2006. "Learning about Menstruation: Cultural Diversity and Knowledge Acquisition." International Journal of Diversity in Organizations, Communities and Nations, Vol. 5.

2. The qualitative ethnographic study included data collected from 48 in-depth interviews from four mother-daughter dyads from six groups that were defined by the origin of the mothers, ages 55-65, who were born in (1) Israel; or immigrated to Israel from: (2) North Africa in the 1950s-1960s; (3) Europe in the 1950s-1960s; (4) the Former Soviet Union (FSU) in the 1970s-1980s; (5) the United States or Canada in the 1970s-1980s; and (6) Ethiopia in the 1980s. The daughters, ages 25-35, met the following criteria: (1) born in Israel or immigrated as children or teens; (2) educated in schools in the Negev; (3) completed undergraduate degrees or equivalent; and (4) given birth to their first child. These daughters were chosen since giving birth marks a critical period in the evolving mother-daughter relationship.

3. Sheryl E. Mendlinger and Julie Cwikel. 2006. "Health Behaviors over the Life Cycle among Mothers and Daughters from Ethiopia." Nashim: A Journal of Jewish Woman's Studies and Gender Issues 12 (Fall): 57-94.

4. Sheryl E. Mendlinger, Julie Cwikel, Rachel Gershaw, and Patricia Ann Farrell. 2011. "Blood Is Thicker than Water: Menarche as a Trigger for MemoriesMother-Daughter Dyads across Cultures.” Unpublished manuscript, Society for Menstrual Cycle Research (SMCR), Pittsburgh, PA.

5. Ibid.

6. Sheryl E. Mendlinger and Julie Cwikel. 2005. "Menstruation and Reproductive Practices-Religion and Traditions and the Influence of Immigration on Mother-Daughter Dyads across Cultures." Unpublished manuscript, Society for Menstrual Cycle Research (SMCR), Boston, MA.

7. Laura E. Warren, Sheryl E. Mendlinger, Katherine A. Corso, and Caprice C. Greenberg. 2012. "A Model of Knowledge Acquisition in Early Stage Breast Cancer Patients." The Breast Journal 18 (1): 69-72. 
Open Access This chapter is licensed under the terms of the Creative Commons Attribution 4.0 International License (http://creativecommons.org/licenses/ by $/ 4.0 /)$, which permits use, sharing, adaptation, distribution and reproduction in any medium or format, as long as you give appropriate credit to the original author(s) and the source, provide a link to the Creative Commons license and indicate if changes were made.

The images or other third party material in this chapter are included in the chapter's Creative Commons license, unless indicated otherwise in a credit line to the material. If material is not included in the chapter's Creative Commons license and your intended use is not permitted by statutory regulation or exceeds the permitted use, you will need to obtain permission directly from the copyright holder. 